\title{
Intensive care unit isolation hood decreases risk of aerosolization during noninvasive ventilation with COVID-19
}

\author{
Kendrick M. Shaw, MD PhD • Angela L. Lang, MD - Rodrigo Lozano • \\ Michele Szabo, MD · Samuel Smith, MD · Jingping Wang, MD PhD
}

Received: 12 May 2020/Revised: 15 May 2020/Accepted: 15 May 2020/Published online: 26 May 2020

(C) Canadian Anesthesiologists' Society 2020

\section{To the Editor,}

The treatment of patients with coronavirus disease (COVID-19) needs to take into consideration not only the disease process but also the availability of medical resources and the risks of transmission to healthcare providers. Noninvasive ventilation (NIV) and oxygenation with high-flow nasal cannula (HFNC) are considered by many to be a high-risk aerosol-generating procedure. ${ }^{1}$ As such, their use is typically avoided in our institution, with mechanical ventilation being the preferred means of respiratory support in patients with COVID-19associated respiratory failure. On a national level, however, the ventilator shortage may necessitate a shift towards NIV and HFNC to ease the pressure on scarce ventilator resources. $^{2}$ The use of HFNC was widely employed in China $^{3}$ and it is also recommended by the European Society of Intensive Care Medicine. ${ }^{4}$ Although there is no direct evidence in patients with COVID-19, HFNC has been shown to reduce the risk of intubation in patients with acute hypoxic respiratory failure compared with conventional oxygen therapy. ${ }^{5}$ To explore the possibility of safely using HFNC in COVID-19 patients, we developed a custom-built intensive care unit isolation hood (ICUIH)

Kendrick M. Shaw and Angela L. Lang have contributed equally to the study.

K. M. Shaw, MD PhD - A. L. Lang, MD - M. Szabo, MD • S. Smith, MD - J. Wang, MD PhD ( $₫)$.

Department of Anesthesia, Critical Care and Pain Medicine, Massachusetts General Hospital, Boston, MA, USA

e-mail: jwang23@mgh.harvard.edu

\section{R. Lozano}

Department of Biomedical Engineering, Massachusetts General Hospital, Boston, MA, USA with the intent to minimize contamination risk from potential aerosols generated with HFNC. The ICUIH is disposable and can provide a negative pressure environment to contain aerosols when used with a smoke plume evacuator (Visiclear $\AA$; Buffalo Filter, Lancaster, NY, USA) or other suction source.

For testing, a humidifier (JB07; Jisulife, Shenzhen, China) was used for continuous aerosol generation in the ICUIH. The HFNC (air/oxygen blender - Micromax; Maxtec, Salt Lake City, UT, USA; flow meter - Blender Buddy 1; Maxtec, Salt Lake City, UT, USA; HFNC: 1600HF-7-25; Salter Labs, Lake Forest, IL, USA) was placed close to the humidifier outlet, and delivered oxygen at a rate of $70 \mathrm{~L} \cdot \mathrm{min}^{-1}$ (Figure, panel A). A laser particle counter (PMS5003; Plantower, Beijing, China) was placed inside the hood on the simulated patient's head and a second laser particle counter was placed outside the hood at approximately head position of a provider. In many cases, the particle count inside the hood exceeded the range of the particle counter for particles between 0.3 and $0.5 \mu \mathrm{m}$ so this range of particles was excluded from the primary analysis. When the particle counts for this range were not saturated, the results for these smaller particles were qualitatively similar to what we report for the $0.5-10 \mu \mathrm{m}$ range of particles, so we do not see this as a significant limitation to our analysis. Finally, the HFNC was placed on the mannequin's head inside the ICUIH and set at a flow rate of $70 \mathrm{~L} \cdot \mathrm{min}^{-1}$.

The particle count outside the ICUIH was consistently more than 1,000 times lower than that of inside (Figure, panels $\mathrm{B}$ and $\mathrm{C}$ ). The median [interquartile range] particle count outside the hood was 155 [70-360] particles $\cdot \mathrm{L}^{-1}$ without negative pressure, which decreased to 50 [30-90] particles $\cdot \mathrm{L}^{-1}$ when a smoke evacuator was at maximum capacity ( $839 \mathrm{~L} \cdot \mathrm{min}^{-1}$ using $22 \mathrm{~mm}$ tubing). The particle 
A

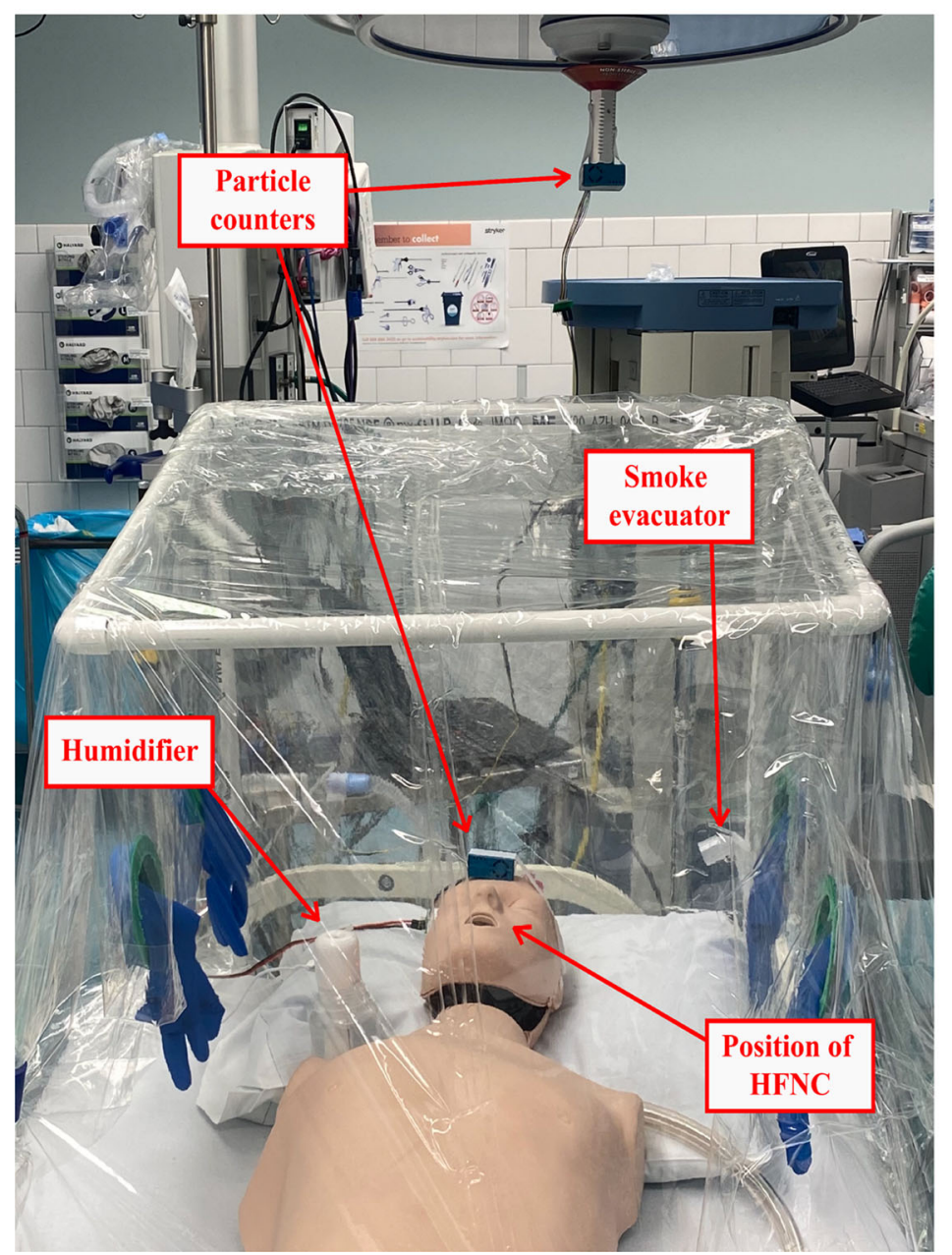

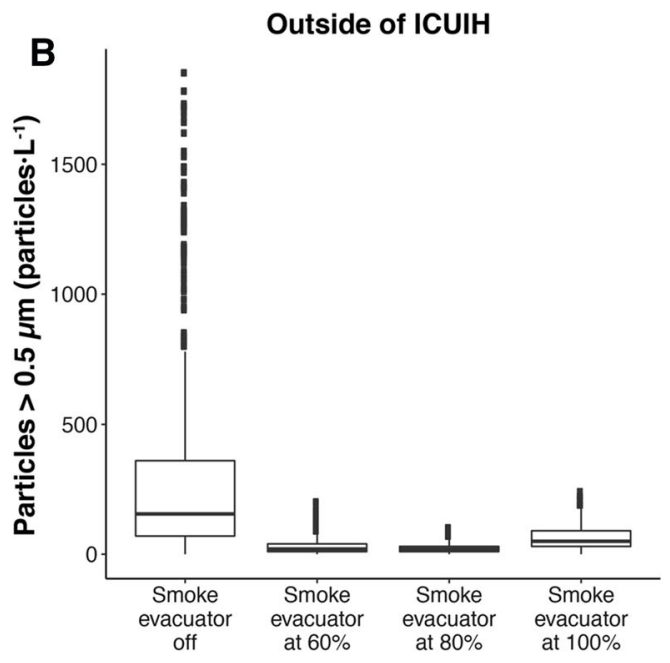

C

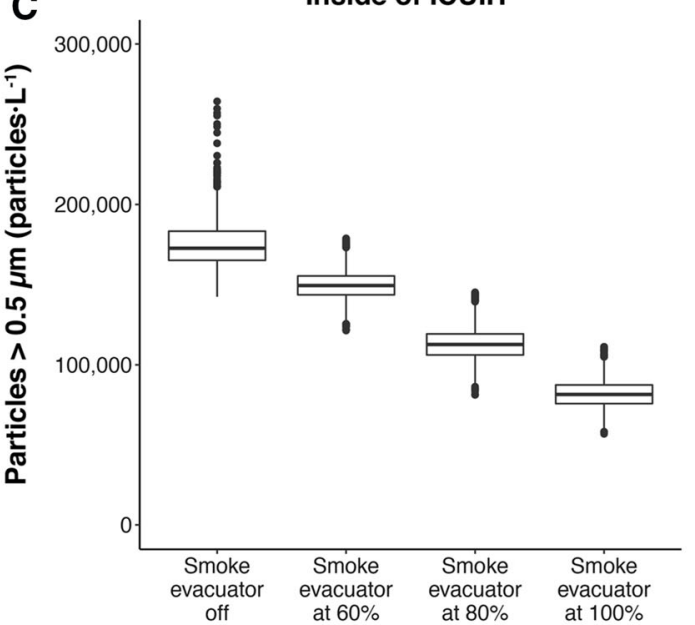

Figure A custom-built negative pressure intensive care unit isolation hood (ICUIH) and its testing. (A) A humidifier was place inside the hood beside the head of the mannequin. A particle counter was place on the forehead of the mannequin inside the hood, and a second counter was placed outside. A high-flow nasal cannula was placed on the head of the mannequin and set at a flow rate of $70 \mathrm{~L} \cdot \mathrm{min}^{-1}$. Variable negative pressure was generated inside the hood using a

count inside the ICUIH was $173,585[165,050-183,282]$ particles $\cdot \mathrm{L}^{-1}$ without negative pressure, and decreased to $81,530[75,770-87,430]$ particles $\cdot \mathrm{L}^{-1}$ when the smoke evacuator was at maximum capacity. This shows that ICUIH can act as an effective physical barrier when HFNC is in use. The rate of aerosol clearance was also measured. Without negative pressure, $87 \mathrm{~min}$ was required for the particle count to decrease by $99 \%$, compared with nine minutes and six minutes when the smoke evacuator was set at $60 \%$ and $80 \%$ capacity, respectively. This shows that the ICUIH can also act as an effective source control when HFNC is in use.

The ICUIH and its testing have several limitations. First, our tests did not account for any potential effects of patient smoke evacuator as a suction system. Particle counts outside (B) and inside (C) the hood during continuous aerosol generation while simulating high-flow nasal cannula use were measured. The middle horizontal lines (in A and B) represent the median, with the upper and lower borders of the box representing the upper and lower quartiles. The top and bottom horizontal lines indicate the range. Dots represent values outside of the 97.5 and 2.5 quartiles.

movements, and this hood may not be suitable for uncooperative or claustrophobic patients. Second, the noise from HFNC combined with that from the smoke evacuator may lead to some level of discomfort. Finally, the air in the ICUIH is cleared by the smoke plume evacuator, which has a built-in ultra-low particulate airgrade filter that has a limited service lifetime. The need for filter replacement increases the cost associated with using ICUIH.

In conclusion, the ICUIH serves as an effective physical barrier and source control for aerosols generated when HFNC is in use (at flow rates as high as $70 \mathrm{~L} \cdot \mathrm{min}^{-1}$ ). This may allow the expanded use of NIV in patients with COVID-19-associated respiratory failure to reduce 
intubation and preserve scarce medical resources such as ventilators. The ICUIH may also enable the use of other NIV management, such as continuous airway pressure and bilevel positive airway pressure during COVID-19 treatment in the ICU.

Disclosures None.

Funding statement Support was provided solely from institutional and/or departmental sources.

Editorial responsibility This submission was handled by Dr. Hilary P. Grocott, Editor-in-Chief, Canadian Journal of Anesthesia.

\section{References}

1. Tran K, Cimon K, Severn M, Pessoa-Silva CL, Conly J. Aerosol generating procedures and risk of transmission of acute respiratory infections to healthcare workers: a systematic review. PLoS One 2012. DOI: https://doi.org/10.1371/journal.pone.0035797.

2. Ranney ML, Griffeth V, Jha AK. Critical supply shortages - the need for ventilators and personal protective equipment during the Covid-19 pandemic. N Engl J Med 2020. DOI: https://doi.org/10. 1056/NEJMp2006141.

3. Liang WH, Guan WJ, Li CC, et al. Clinical characteristics and outcomes of hospitalised patients with COVID-19 treated in Hubei (epicenter) and outside Hubei (non-epicenter): a nationwide analysis of China. Eur Respir J 2020. DOI: https://doi.org/10. 1183/13993003.00562-2020.

4. Alhazzani W, Moller MH, Arabi YM, et al. Surviving Sepsis Campaign: Guidelines on the Management of Critically Ill Adults with Coronavirus Disease 2019 (COVID-19). Intensive Care Med 2020; 46: 854-87.

5. Rochwerg B, Granton D, Wang DX, et al. High flow nasal cannula compared with conventional oxygen therapy for acute hypoxemic respiratory failure: a systematic review and meta-analysis. Intensive Care Med 2019; 45: 563-72.

Publisher's Note Springer Nature remains neutral with regard to jurisdictional claims in published maps and institutional affiliations. 